\title{
Industry 4.0 competencies among lecturers of higher learning institution in Malaysia
}

\author{
Tan Owee Kowang', Mohamad Fawzy Bakry², Ong Choon $\mathrm{Hee}^{3}$, Goh Chin $\mathrm{Fei}^{4}$, Lim Kim Yew ${ }^{5}$, \\ Mohd Saiful Izwaan Saadon ${ }^{6}$, Choi Sang Long ${ }^{7}$ \\ 1,2,3,4Azman Hashim International Business School, Universiti Teknologi Malaysia, Malaysia \\ ${ }^{5}$ Faculty of Business, Communication \& Law, INTI International University, Malaysia \\ ${ }^{6}$ Universiti Malaysia Terengganu, Malaysia \\ ${ }^{7}$ Raffles University, Malaysia
}

\begin{tabular}{l} 
Article Info \\
\hline Article history: \\
Received Feb 9, 2020 \\
Revised Mar 12, 2020 \\
Accepted Apr 29, 2020 \\
\hline
\end{tabular}

Keywords:

Competencies

Focus index

Higher education

Improvement

Industry 4.0

\begin{abstract}
Industry 4.0 is a new breed from the past industry revolution. The revolution implies an inevitable impact on professional sectors, including education field. Higher Learning Institution (HLI) is viewed as the platform for the development of Industry 4.0 competencies. However, research related to Industry 4.0 competencies among educators or academicians is scarce. Hence, this study aims to assess the level of Industry 4.0 competencies among lecturers in one of higher learning institution in Malaysia, as well as to identify Industry 4.0 competencies that required further enhancement. Five Industry 4.0 competencies identified from literature review, which are Information and Communication Technologies (ICT), Organizational Learning, Innovative Management, Environment and Continuous Improvement competencies. The importance level and implementation level perceived by the lecturers across the five competencies are assessed via questionnaire which responded by 132 lecturers from a higher learning institution in Malaysia. Data collected is analyzed via descriptive analysis to assess the importance and implementation levels perceived by the respondent. In addition, an improvement opportunity index, namely Focus Index is calculated for each competency. Finding from the study reveals that all the four Industry 4.0 competencies are perceived by respondents as important, however implemented at moderate level. Analysis result of Focus Index also suggests that competencies in term of Organizational Learning and ICT are "over focus", while Environment competency is viewed as "under focus" which required further enhancement.
\end{abstract}

This is an open access article under the CC BY-SA license.

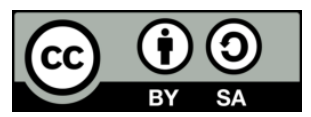

\section{Corresponding Author:}

Tan Owee Kowang,

Azman Hashim International Business School,

Universiti Teknologi Malaysia,

81310, Johor Bahru, Johor, Malaysia.

Email: oktan@utm.my

\section{INTRODUCTION}

Industry 4.0 is a new breed from the past industry revolution. It focuses on smart factory as its core content [1] and it also even change the way people work [2]. Besides professional sectors, industry 4.0 also implies an inevitable impact on higher learning institution (HLI) because HLI is being viewed as the platform to develop the competencies that is essential for the adoption of Industry 4.0, such as knowledge of digital technologies; real time data gathering and analysis; Internet of Things (IoT), cloud services as well as big 
data, or namely the competencies of Industry 4.0 [3]. As such, the level of Industry 4.0 competencies among lecturers in HLI is crucial for the institution to react with the changes that driven by Industry 4.0. Thus, the purpose of this research is to assess the level of Industry 4.0 competencies among lecturers within one of the higher learning institution in Malaysia. The research also aim to identify improvement opportunities related to Industry 4.0 competencies.

\section{LITERATURE REVIEW}

\subsection{Competencies}

Competencies in individual aspect is a set of behavior, abilities, skills, analysis, decision making and transmission of information that are required to carry out his or her position in an occupation [4]. In addition, competencies are personal skills that reflect potential ability to provide a consistently adequate or high level of performance in a specific job function $[5,6]$. Competencies could be divided further into three categories, which are technical competency, behavioral competency and contextual competency [5]. In contrast, competencies according to organization is learning environment, exploration of acquired experience, constant learning, skill development and improvement process, continuous creation of knowledge, exchange of information and knowledge and rapid learning [7].

\subsection{Industry 4.0}

Industry 4.0 refers to digitalization transformation of production or manufacturing based industries which driven by connected technologies, namely cyber-physical systems, internet of things, cloud computing and cognitive computing [1,8]. Industry 4.0 allows real time and decentralized communication, monitoring, coordination, controlling of physical process value streams (i.e. machinery and equipment) with the ultimate aim to optimize resource utilization and satisfying customers demand [9]. As such, the uniqueness of Industry 4.0 could be viewed from four perspectives. The first perspective is interconnection, the second perspective is information transparency following technical assistance in the third perspective and the fourth perspective is decentralized decision.

\subsection{Industry 4.0 competencies}

Higher Learning Institution is viewed as the platform to develop the competencies that is essential for the adoption of Industry 4.0 [10]. As such, higher learning institutions need to combat with innovative, open, and flexible learning environments in order to prepare the students to have Industry 4.0 mentality or skills to get ready for future working ecosystem. Thus, the lecturers have to learn and able to cope with the new emerging learning landscape such as virtual collaboration, technological convergence, global connectivity, online communities, and digital creativity (Karakas). In addition, lecturers have to be creative in terms of curricular activities by providing problem based, integrated and draw on people assignments [10]. Based on finding from literature review, there are four important aspects of Industry 4.0 competencies suggested by prior studies, which are information and communication technologies, organizational learning, innovative management and environment $[4,11]$.

\subsubsection{Information and communication technologies}

Information and communication technologies competencies can be possessed if an individual has acquired a sufficient expertise in Internet of Things (IoT), big data, cloud computing and other Industry 4.0 technologies [4]. Data and information sharing is one of the core principle of cyber physical system for collaborating computational manufacturing processing elements and controlling manufacturing physical entities, which are supported by IoT, Cloud computing and Big data [12]. Within the context of Higher Learning Institution (HLI), the knowledge or competency of information and communication technology among educators or lecturers is vital for the HLT to serve as platform of preparing undergraduate to embrace into the Industry 4.0 ecosystem [13]. As such, the workplace or the institution should be furnished with ICT equipment, software and tools in order to nurture the knowledge and skills of ICT among workers or lecturers.

\subsubsection{Organizational learning}

Organizational learning refers to the organizational adaptation toward changing of environment [7]. Organizational adaptability is the essence of organization learning and its performance will affect the organization's ability to learn and adapt in a changing environment [11]. The adaptation process involves multiple levels of learning within an organization, which made up of individual learning, group learning and organization learning. Development of organizational learning competency involves several steps, including the process of developing learning skill on dealing with environmental change; exploration of the experience 
gained, creation of knowledge, information and knowledge sharing within individuals as well as speed of learning [7]. Within the context of Industry 4.0, organization learning competency is particularly crucial. This is because the teaching and learning process in the $21^{\text {st }}$ century digital world is demanding educators or lecturers to be attained with skill and knowledge of industry 4.0 related technologies.

\subsubsection{Innovation management}

Innovative management is a vital element of Industry 4.0 competencies because it promotes creative thinking via Industry 4.0 technologies such as Virtual Reality (VR) and simulation. VR is a human-computer interfaces medium via integrating digital object into the real world for creative expression and communication. With VR, teaching and learning process could be carried out with the most appropriate interactivity option that match student performance characteristics as well as compatible with a learner's learning style.

Within the context of teaching and learning process in HLI, innovative management could be viewed as the ability to adopt new teaching and learning models [4]. Such as transforming the traditional teaching and learning process to an open based education via Massive Open Online Course (MOOCs). MOOCs is originated within the ideals of openness in education, that knowledge should be shared freely and the desire to learn should be met without demographic, economic, and geographical constraints, which is in line with the decentralized concept of Industry 4.0.

\subsubsection{Environment}

Environment competency refers to the creative skills and interdisciplinary thinking of lecturer in respect to creating a teaching and learning environment that nurture the learning process of $21^{\text {st }}$ century. Study done by prior scholars suggested that creative classroom activities speed up the learning process and enhanced students 'performance [14-16]. Hence, creative skills are an important factor to be instilled in every educator or lecturer in the higher learning institution; whereas, interdisciplinary thinking promotes the development of boundary-crossing skills [17]. Interdisciplinary thinking helps to address complex and multidisciplinary subject matter such as knowledge and skill of industry 4.0. It is believed that a crossdisciplinary approach facilitates a comprehensive understanding [17]. Ecosystem that supports teaching and learning in 21 st century could be established via a creative and interdisciplinary teaching and learning environment, hence the competency of creating such learning environment is another important element of Industry 4.0 competency for HLI.

\subsubsection{Continuous improvement}

Continuous improvement or also known as Kaizen is a gradual and continuous progress, increase of value, intensification and improvement $[18,19]$. In order for a HLI to be competitive in this continuously changing environment, the HLI need to continuously review and analyses the market need and expectation of stack holders, as well as to re-visit and re-evaluate the teaching and learning process to ensure it is meeting both market and stack holders' expectation. As such, the capability of the organization and individual (including lecturers) to continuously improve particularly on the teaching and learning process become imperative [20]. Hence, continuous improvement become one of important pillar for Industry 4.0 competency in HLI.

\subsection{Research framework}

Figure 1 shows the research framework for this study. The research focus on studying of the intergap among lecturers' expectation (i.e. important level) and perception (i.e. implementation level) of Industry 4.0 competencies; which is defined as Gap 5 in the Model of Service Quality Gaps [21]. 


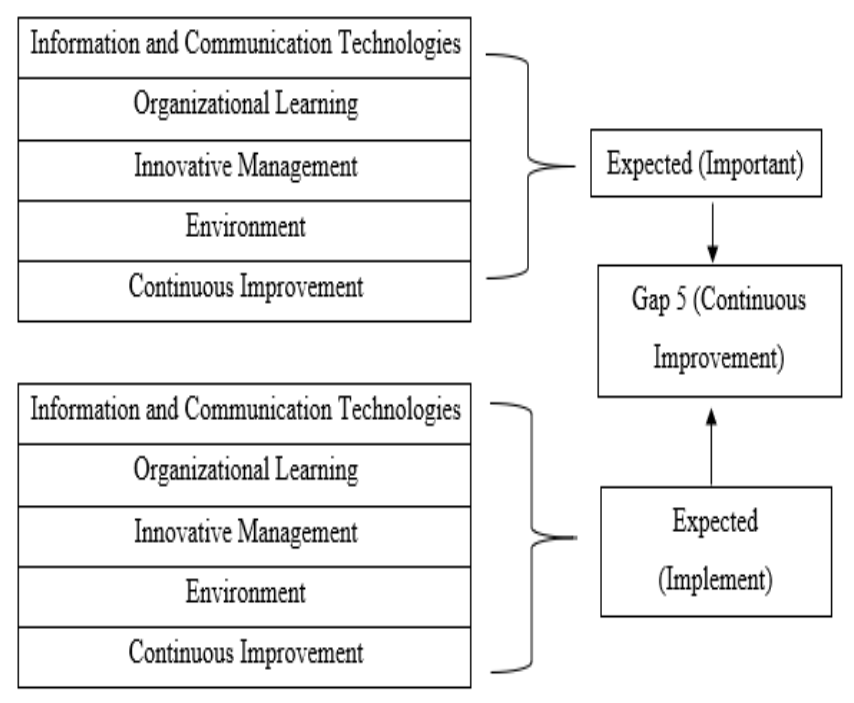

Figure 1. Research framework

\section{RESEARCH METHOD}

This research is quantitative based. The perceived important level and implementation level of Industry 4.0 competencies are assessed via structured questionnaire.

\subsection{Population and sampling}

The population of study (i.e. lecturers from one of the higher learning institution in Malaysia) is counted as 308 lecturers and the designated sample size is 175 persons. The sampling size is derived based on Krejcie and Morgan [22] sampling table which stated that for the population of 320 persons, the targeted sample size should be 175 .

\subsection{Research instrument}

The study is quantitative based. The questionnaire used in the research consists of two sections. Section A to collect the respondent demographic information, while Section B assessing the importance level and implementation level placed by the respondents on the five Industry 4.0 competencies that discussed in section 2.0, which are information and communication technologies, organizational learning, innovative management and environment competencies. The assessment was done via 5-points scales from "1" representing "Not important" or "No implementation" to "5" indicating "Extremely important" "Fully implemented".

\subsection{Analysis tool}

\subsubsection{Descriptive analysis}

The normality and reliability of data collected from part B of questionnaire are assessed via Skewness \& Kurtosis value and Cronbach Alpha test respectively. Skewness and Kurtosis range of +/- 2 represents data is normally distributed. Meantime, Cronbach Alpha reliability value of greater than 0.60 is suggested to be adequate for testing the reliability of factors [23]. Subsequently, the mean of importance level scores and implementation level scores for each of the Industry 4.0 competency is derived in order to assess the important and implementation level based on the scale proposed by Tan and Rasli [23] refers to Table 1.

Table 1. Important and implementation level

\begin{tabular}{ccc}
\hline \multicolumn{2}{c}{ Important and Implementation Level Rating Scale } \\
Mean $(\mu)$ & Importance Level & Implementation Level \\
\hline $1.0 \leq \mu<1.5$ & Not Very Important & No Implementation \\
$1.5 \leq \mu<2.5$ & Not Important & Low Implementation \\
$2.5 \leq \mu<3.5$ & Neutral & Moderate Implementation \\
$3.5 \leq \mu<4.5$ & Important & High \\
$4.5 \leq \mu \leq 5.0$ & Very Important & Full Implementation \\
\hline
\end{tabular}




\subsubsection{Focus index}

Focus index is a descriptive analysis tools developed by Tan and Rasli [23] to identify improvement opportunity. Traditionally, implementation level was used as the reference point for identifying improvement opportunity. i.e. item or attribute with the lowest implementation level is perceived in social science research as item or attribute that required further enhancement [23]. Conceptually, implementation level for an attribute is a standalone measure that without taking into consideration the importance level of the attribute. As the consequences, an attribute with low implementation level might not necessary calls for improvement if the importance level of the attribute is relatively low. As such, a better approach of identifying improvement opportunity is to assess implementation level in relative to importance level [23]. In conjunction with this, Focus Index was developed to explore improvement opportunity by taking into account both importance level and implementation level. Focus Index refers to the ratio between ranking number of important level and ranking number of effectiveness.

$$
\text { Focus Index }(F I)_{\text {Competency } 1}=\frac{\text { Ranking number of Importance Level }}{\text { Competency } 1}
$$

Ranking number is defined based on the mean score of important level and implementation effectiveness. Since this study involves five Industry 4.0 competencies, competency with the highest mean score is ranked as 1 , while competency with the lowest mean score is ranked as 5. Implementation effectiveness is derived by dividing implementation level with important level.

$$
\text { Effectiveness }_{\text {Competency } 1}=\frac{\text { Implementaion Level }_{\text {Competency } 1}}{\text { Importance Level }_{\text {Competency } 1}} \times 100 \%
$$

Competency with Focus Index of 1 representing the competency is focused at the appropriate level. While Focus Index of more than 1 indicates that the competency is "over focus", and Focus Index of less than 1 suggests that it is "under focus", hence prompt for further improvement or enhancement.

\section{RESULTS AND DISCUSSION}

The total number of respondents that have answered the questionnaires is 132 out of the sample size of 175 , hence, the respond rate for this research is $75 \%$. All questionnaires are screened and there is no issue of missing value across all the 132 returned questionnaires.

\subsection{Normality and reliability test}

Result of normality test for all measurement items shown that the value of Skewness and Kurtosis are within -2 and +2 , hence there is no issue in regard with data normality [24]. In addition, Cronbach Alpha reliability ranged from 0.856 to 0.902 . This implies that the data is statistically significant to proceed for further analysis $[25,26]$.

\subsection{Importance level of industry 4.0 competencies}

To address RO1 (To assess the importance level of industry 4.0 competencies perceived by lecturers within higher learning institution in Malaysia), the mean important level score for the five Industry 4.0 competencies is ranked accordingly based on the mean score and summarized in Table 2.

Table 2. Importance level

\begin{tabular}{ccc}
\hline \multicolumn{2}{c}{ Important Level of Industry 4.0 Competencies } & Mean \\
Industry 4.0 Competency & Level* \\
\hline Environment & 4.32 & Important \\
Continuous Improvement & 4.15 & Important \\
Organizational Learning & 4.10 & Important \\
Information and Communication Technologies (ICT) & 4.05 & Important \\
Innovative Management & 3.81 & Important \\
\hline *refer to Table 1 for rating scale & &
\end{tabular}

As refers to Table 2, respondents regarded that all Industry 4.0 competencies are important for lecturers in higher learning institution. Environment competency is viewed by respondents as the most important competency with the mean score of 4.32. While Innovative Management is suggested by 
respondent is the least important competency with mean score of 3.81. The finding is consistent with the study done by prior scholars $[4,27,28]$ which suggested that the five competencies are the fundamental needs for competitive advantage in the era of Industry 4.0 regardless of economy sector.

\subsection{Implementation level of industry 4.0 competencies}

To address RO2 (To evaluate the implementation level of industry 4.0 competencies perceived by lecturers within higher learning institution in Malaysia), the implementation level for each Industry competency is calculated and summarized in Table 3.

Table 3. Implementation level

\begin{tabular}{ccc}
\hline \multicolumn{2}{c}{ Implementation Level of Industry } & 4.0 Competencies \\
Ind 4.0 Competency & Mean & Level* \\
\hline Organizational Learning & 3.55 & Moderate \\
Continuous Improvement & 3.56 & Moderate \\
Information and Communication Technologies & 3.44 & Moderate \\
Environment & 3.59 & Moderate \\
Innovative Management & 3.03 & Moderate \\
\hline *refer to Table 1 for rating scale & &
\end{tabular}

Based on the Table 3, all the five Industry 4.0 competencies are perceived by the respondents as implemented at moderate level with the mean ranges from 3.03 (for Innovative Management competency) to 3.59 (Environment competency). In addition, implementation level for all Industry 4.0 competencies is lower than the important level perceived by the respondents. Hence, finding from the analysis result suggested that there is a need to enhance the Industry 4.0 competencies among lecturer in higher learning institution within Malaysia across all the five competencies. As such, the approach used to identify and prioritize improvement opportunity is crucial to ensure that the improvement efforts are focused on the correct competency [23, 29, 30].

\subsection{Improvement opportunity for industry 4.0 competencies}

To address the research objective 3 of this study (i.e to identify the improvement opportunity of industry 4.0 competencies for higher learning institution in Malaysia), Focus Index for each competency is calculated and summarizes in Table 4.

Table 4. Focus index

\begin{tabular}{cccccc}
\hline Ind. 4.0 Competency & \multicolumn{2}{c}{ Important } & \multicolumn{2}{c}{ Implementation } & \multicolumn{2}{c}{ Focus } \\
& Level & Rank & $\%$ & Rank & Index \\
\hline ICT & 4.05 & 4 & 84.9 & 3 & 1.33 \\
Organization Learning & 4.10 & 3 & 86.6 & 1 & 3 \\
Innovative Management & 3.81 & 5 & 79.6 & 5 & 1 \\
Environment & 4.32 & 1 & 83.2 & 4 & 0.25 \\
Continuous Improvement & 4.15 & 2 & 85.8 & 2 & 1 \\
\hline
\end{tabular}

Based on Table 4, Organizational Learning and Information and Communication Technologies are regarded by respondents as "over focus" which is reflected by the Focus Index of over 1 (i.e. 3 and 1.33 respectively). Meantime, Innovative Management and Continuous Improvement competencies donated the Focus Index of 1 suggested that both competencies are focused at the correct level. However, Environment competency which with the Focus Index value of 0.25 indicates that the competency is under focus and requires further improvement.

Hence, within the context of lecturers in higher learning institution, finding from this research suggested that in order to enhance competitive advantage of Industry 4.0 competencies among HLI in Malaysia, lecturers in the HLI have to focus on continuously improving teaching and learning environment, with the ultimate aim to create an ecosystem that supports teaching and learning process in the 21 st century digitalization that driven by Industry 4.0. Perhaps one of the approaches to improve Environment competency is by exposing Interdisciplinary teaching among lecturers from different faculty or different expertise. This approach potentially could enhance boundary-crossing skills, synthesizing knowledge of different disciplines and coping with complexity that in line with the nature of Industry 4.0 [17]. 


\section{CONCLUSION}

Industry 4.0 or the fourth industry revolution compel academic fields to combat with innovative, open, and flexible learning environments in order to prepare the students to have Industry 4.0 mentality or skills to get ready for future working ecosystem. As such the competencies of lecturer in related to Industry 4.0 become crucial for the teaching and learning process as well as for higher learning institution. This research outline a systematic approach to assess the important level, implementation level and implementation effectiveness of Industry 4.0 competencies among lecturers of higher learning institution. The research also introduced Focus Index as descriptive analysis tool to identify and prioritize competency areas that required further improvement. Hence, finding from this study has descriptive value in terms of assessing Industry 4.0 competencies as well as identify improvement opportunity which is significant to the literature and study of Industry 4.0.

\section{ACKNOWLEDGEMENTS}

Authors wish to acknowledge the Malaysian Ministry of Education and Universiti Teknologi Malaysia under the Research Grant (Vote No. 5F136) for sponsoring this publication.

\section{REFERENCES}

[1] H. Kagermann, et al., "Recommendations for implementing the strategic initiative INDUSTRIE 4.0: Securing the future of German manufacturing industry," Final report of the Industries 4.0 Working Group, 2013.

[2] T. Stock, et al., "Industry 4.0 as enabler for a sustainable development: A qualitative assessment of its ecological and social potential," Process Safety and Environmental Protection, vol. 118, pp. 254-267, 2018.

[3] J. Lee, et al., "A cyber-physical systems architecture for industry 4.0-based manufacturing systems," Manufacturing Letter, vol. 3, pp. 18-23, 2015.

[4] M. D. Bermúdez and B. Juárez, "Competencies to adopt Industry 4.0 for operations management personnel at automotive parts suppliers in Nuevo Leon," Proceedings of the International Conference on Industrial Engineering and Operations Management 2017, pp. 736-747. 2017.

[5] S.N. Kamaruzzaman, et al., "Developing facilities management (FM) competencies for Malaysia: Reference from international practice," Journal of Facilities Management, vol. 16, no. 2, pp. 157-174. 2018.

[6] N.L. Mace, Teaching dementia care: Skill and understanding. JHU Press, 2005.

[7] M. Dasgupta, "Organizational Learning and its Practices: A Review," SAGE Open, 2012. [Online]. Available: SSRN: https://ssrn.com/abstract=2105990

[8] P. Gaj, et al., "Computer communication within industrial distributed environment-A survey," IEEE Transactions on Industrial Informatics, vol. 9, no. 1, pp. 182-189, 2012.

[9] M.M. Lopez, et al., "Conditional variational autoencoder for prediction and feature recovery applied to intrusion detection in IoT”. Sensors, vol. 17, no. 9, 2017

[10] Buasuwan, P. J. A. E. and Studies, D., "Rethinking Thai higher education for Thailand 4.0," Asian Education and Development Studies, vol. 7, no. 2, pp. 157-173, 2018.

[11] O. K. Tan, et al., "Industry 4.0 Competencies for Production Equipment Manufacturers in Malaysia," International Journal of Academic Research in Business and Socal Sciences, vol. 9, no. 2, pp. 300-311, 2019.

[12] A. Al-Fuqaha, et al., "Internet of things: A survey on enabling technologies, protocols, and applications," IEEE Communications Surveys \& Tutorials, vol. 17, no. 4, pp. 2347-2376, 2015.

[13] H. Aldowah, et al., "Issues and challenges of using e-learning in a Yemeni Public University," Indian Journal of Science and Technology, vol. 8, no. 32, pp. 1-9, 2015.

[14] T. De Jong, "Learning and instruction with computer simulations," Education and Computing, vol. 6, no. 3-4, pp. 217-229, 1991

[15] Z. Merchant, et al., "Effectiveness of virtual reality-based instruction on students' learning outcomes in K-12 and higher education: A meta-analysis," Computers \& Education, vol. 70, pp. 29-40, 2014.

[16] S. Tobias, et al., "Game-based learning. In Handbook of research on educational communications and technology," Springer, 2014.

[17] E. J. Spelt, et al. "Teaching and learning in interdisciplinary higher education: A systematic review," Educational Psychology Review, vol. 21, no. 4, p. 365, 2009.

[18] T. Karkoszka, et al., "Risk of the processes in the aspect of quality, natural environment and occupational safety," Journal of Achievements in Materials and Manufacturing Engineering, vol. 20, no. 1-2, pp. 539-542, 2017.

[19] J. Singh, et al., "Continuous improvement philosophy-literature review and directions," Benchmarking An International Journal, vol. 22, no. 1, pp. 75-119, 2015.

[20] D. Carlucci, et al., "Assessing teaching performance in higher education: a framework for continuous improvement," Management Decision, vol. 57, no. 2, pp. 461-479, 2019.

[21] A. Parasuraman, et al., "A conceptual model of service quality and its implications for future research," Journal of Marketing, vol. 49, no. 4, pp. 41-50, 1985.

[22] R. V. Krejcie, et al., "Determining sample size for research activities," Educational and Psychological Measurement, vol. 30, no. 3, pp. 607-610, 1970. 
[23] O. K. Tan, et al., "Application of Focus Index in New Product Development," Procedia-Social and Behavioral Sciences, vol. 40, pp. 446-450, 2012.

[24] R.A. Groeneveld, et al., "Measuring skewness and kurtosis," Journal of the Royal Statistical Society, vol. 33, no. 4, pp. 391-399, 1984.

[25] J. P. Gee, "What video games have to teach us about learning and literacy," Computers in Entertainment (CIE), vol. 1, no. 1, pp. 20-20, 2003.

[26] S. S. Shapiro, et al, "An analysis of variance test for normality (complete samples)," Biometrika, vol. 52, no. 3/4, pp. 591-611, 1965.

[27] Y. Liao, et al., "Past, present and future of Industry 4.0-a systematic literature review and research agenda proposal," International Journal of Production Research, vol. 55, no. 12, pp. 3609-3629, 2017.

[28] H. J. J. McLellan, et al., "Virtual reality and multiple intelligences: Potentials for higher education," Journal of Computing in Higher Education, vol. 5, no. 2, pp. 33-66. 1994.

[29] Y. Liu, et al., "Industry 4.0 and Cloud Manufacturing: A Comparative Analysis," Journal of Manufacturing Science and Engineering, vol. 139, no. 3, 2017.

[30] J. M. Müller, et al., "What Drives the Implementation of Industry 4.0? The Role of Opportunities and Challenges in the Context of Sustainability," Sustainability, vol. 10, no. 1, p. 247, 2018. 